\title{
ORIGINAL ARTICLE PREDICTORS OF MULTIVESSEL CORONARY ARTERY DISEASE IN YOUNG PATIENTS PRESENTING WITH ST-SEGMENT ELEVATION MYOCARDIAL INFARCTION
}

\author{
Ayaz Mir', Syed Zia Ullah', Atif Sher Muhammad ${ }^{1}$, Faiza Farooq ${ }^{1}$, Ali Ammar¹, Javaid Ur \\ Rehman $^{1}$, Tahir Saghir ${ }^{1}$ \\ ${ }^{1}$ National Institute of Cardiovascular Diseases, Karachi, Pakistan
}

\begin{abstract}
Objectives: Premature coronary artery disease (CAD) is on the rise in our population, and multivessel disease (MVD) is no longer an uncommon finding in young patients. Therefore, aim of this study was to determine the predictors of MVD in young patients who presented with ST-Segment Elevation Myocardial Infarction (STEMI).

Methodology: For this study, we enrolled 294 young adult (18-40 years) patients with STEMI. MVD was diagnosed based on angiography. Demographic characteristics and baseline risk profiles were considered for the univariate and multivariate analyses to determine the predictors of MVD.

Results: Out of 294 patients, $90.5 \%$ (266) were males, and the mean age was $35.45 \pm 4.07$ years. Our $24.1 \%$ (71) patients were hypertensive (HTN), and $36.1 \%$ (106) were smokers. A total of 94 patients had MVD. Patients with MVD were older and more likely to have diabetes (DM) and HTN than their counterparts. Only age and DM were found to be significant independent predictors of MVD. The risk of developing MVD was higher in diabetics, with adjusted odds ratios (ORs) [95\% CI] of 2.47 [1.23-4.97; $\mathrm{p}=0.011]$.

Conclusion: In conclusion, we showed that age and DM are independent predictors of MVD in a young Pakistani adult population presenting with STEMI. However, none of the other risk factors, such as obesity, male gender or smoking, were found to be significantly associated with MVD in Pakistani adults with premature CAD. Although significantly associated, HTN does not prove to be an independent predictor of multivessel CAD in young adults .

Keywords: coronary artery diseases, young, ST-segment elevation myocardial infarction, primary percutaneous coronary intervention, multivessel disease, single-vessel disease

Citation: Mir A, Ullah SZ, Muhammad AS, Farooq F, Ammar A, Rehman RU, Saghir T. Predictors of Multivessel Coronary Artery Disease in Young Patients Presenting with ST-Segment Elevation Myocardial Infarction. Pak Heart J. 2021;54(03):268-272. DOI: https://doi.org/10.47144/phj.v54i3.2168
\end{abstract}

\section{INTRODUCTION}

Acute myocardial infarction (AMI) remains the most fatal manifestation of coronary artery disease and may lead to sudden cardiac death. Once considered a disease in older people, the incidence of AMI in younger populations has slowly increased. ${ }^{1,2}$ Several studies have reported a $1-16 \%$ prevalence of AMI in young populations. ${ }^{1-8}$ Several causes and risk factors for premature MI have been highlighted, including mental stress, excessive workload, smoking, sedentary lifestyle, unhealthy dietary habits, and addiction. ${ }^{2,6}$

Although AMI in young individuals has a relatively better prognosis, ${ }^{9-11}$ its social and economic burden is critical for both family and society during the productive years of life. ${ }^{12}$ Its clinical presentation, disease anatomy and risk profile are also dissimilar compared to those of older individuals. ${ }^{1}$ Some studies have also reported that premature MI is more likely associated with smoking, male gender, dyslipidemia and positive family history and is less associated with diabetes mellitus (DM) and hypertension (HTN). ${ }^{1,6}$

In a study conducted by Ge J et al. MVD was found to be associated with an increased MACE rate compared to SVD in young patients with coronary artery disease. ${ }^{13}$ It is also noted that disease recurrence and readmissions are higher in patients with multivessel disease. ${ }^{14}$ It is evident that the risk factors for MVD need to be extrapolated in clinical trials to reduce the burden of coronary artery disease in young populations and to protect their potential productive years of life. The aim of this study was to determine the predictors of multivessel coronary artery disease (MVD) in young patients who presented with STSegment Elevation Myocardial Infarction (STEMI).

\section{METHODOLOGY}

This was a retrospective, cross-sectional, single-center study performed at a tertiary care cardiac center, Karachi in 2018. We enrolled 294 young adult patients aged 18-40 years who presented with STEMI, 
underwent PPCI. This study was approved by the ERC of our hospital, and the ERC waived consent, as general consent had already been obtained from patients at the time of admission. No patients with a prior history of coronary intervention or cardiac surgery were included in the study.

All patients were diagnosed with STEMI as defined by the criteria of the 2015 AHA STEMI guidelines. ${ }^{15}$ Patients were classified as having single-vessel disease (SVD), 2-vessel disease (2VD) or 3-vessel disease (3VD), and patients with either 2VD or 3VD were considered to have multivessel disease (MVD). We documented all demographic variables, including age, gender, obesity, HTN, smoking, lipid profile and random blood glucose. We defined HTN as defined by the Eighth Joint National Committee on HTN and smoking according to the National Health Interview Survey. ${ }^{16} \mathrm{We}$ also followed guidelines to define obesity and dyslipidemia. ${ }^{17,18}$

Statistical Package for Social Sciences (SPSS 21) was used for the data analysis. Descriptive statistics such as the mean $\pm \mathrm{SD}$, median (IQR), maximum and minimum were calculated for quantitative (continuous) variables, and frequencies and percentages were calculated for categorical variables. The t-test or Mann-Whitney $U$ test was used, as appropriate, for the comparison of continuous variables between SVD and MVD groups; similarly, the Chi-square test or Fisher's Exact test was performed to evaluate the categorical variables. Univariate and multivariate logistic regression analyses were performed to assess the predictors of MVD. The result of the logistic regression analysis was expressed as an odds ratio (OR) along with a $95 \%$ confidence interval (CI). Criteria for statistical significance were considered as a p-value of less than or equal to 0.05 .

\section{RESULTS}

We collected data from 294 patients, with $90.5 \%$ (266) males and mean age of $35.45 \pm 4.07$. Overall, $24.1 \%$ patients (71) were hypertensive, and $36.1 \%$ (106) were smokers. The demographic characteristics are outlined in Table 1.

Table 1: Baseline clinical and demographic characteristics

\begin{tabular}{|c|c|}
\hline Characteristics & Total \\
\hline Total (N) & 294 \\
\hline Gender & $90.5 \%(266)$ \\
\hline Male & $9.5 \%(28)$ \\
\hline Female \\
\hline Age (years) \\
\hline Range & $40-23$ \\
\hline
\end{tabular}

\begin{tabular}{|c|c|}
\hline Mean \pm SD & $35.45 \pm 4.07$ \\
\hline Median $[\mathrm{IQR}]$ & $36[39-33]$ \\
\hline Body Mass Index $\left(\mathbf{k g} / \mathbf{m}^{\mathbf{2}}\right)$ & $42.83-15.63$ \\
\hline Range & $26.28 \pm 3.92$ \\
\hline Mean \pm SD & $25.93[28.58-23.51]$ \\
\hline Median [IQR] & $80-200$ \\
\hline SBP $(\mathbf{m m H g})$ & $120.7 \pm 18.7$ \\
\hline Range & $120[130-110]$ \\
\hline Mean \pm SD & $13.9 \%(41)$ \\
\hline Median [IQR] & $0.7 \%(2)$ \\
\hline Risk Factors & $24.1 \%(71)$ \\
\hline Diabetes mellitus & $36.1 \%(106)$ \\
\hline Dyslipidemia & $7.8 \%(23)$ \\
\hline Hypertension & $0.7 \%(2)$ \\
\hline Smoking & $0.3 \%(1)$ \\
\hline Family history CAD & Currently on dialysis \\
\hline Chronic lung disease & standard deviation, \\
\hline CAD = coronary artery diseases, \\
IQR=interquartile range
\end{tabular}

Out of 294 patients, 94 had MVD, while the rest of them had non-MVD. HTN was found in 30 patients $(31.9 \%)$ in the MVD group and in 41 patients $(20.5 \%)$ in the non-MVD group. These clinical characteristics are detailed in Table 2.

Table 2: Demographic and clinical characteristics by multivessel disease

\begin{tabular}{|c|c|c|c|}
\hline \multirow{2}{*}{ Characteristics } & \multicolumn{2}{|c|}{ Multivessel Disease } & \multirow{2}{*}{$\begin{array}{l}* * \text { p- } \\
\text { value }\end{array}$} \\
\hline & No & Yes & \\
\hline $\mathbf{N}$ & 200 & 94 & - \\
\hline \multicolumn{4}{|c|}{ Clinical characteristics } \\
\hline $\begin{array}{l}\text { Age (median } \\
{[\text { IQR]) years }}\end{array}$ & $\begin{array}{c}36 \\
{[39-32]}\end{array}$ & $\begin{array}{c}37 \\
{[40-35]}\end{array}$ & $0.003 *$ \\
\hline $\begin{array}{l}\text { BMI (median } \\
[\mathrm{IQR}]) \mathrm{kg} / \mathrm{m}^{2}\end{array}$ & $\begin{array}{c}25.71 \\
{[28.63-23.28]}\end{array}$ & $\begin{array}{c}26.22 \\
{[28.41-24.49]}\end{array}$ & 0.235 \\
\hline $\begin{array}{l}\text { SBP (median } \\
{[\text { IQR]) mmHg }}\end{array}$ & $\begin{array}{c}120 \\
{[130-110]}\end{array}$ & $\begin{array}{c}110 \\
{[130-110]}\end{array}$ & 0.535 \\
\hline Male gender & $183(91.5 \%)$ & $83(88.3 \%)$ & 0.383 \\
\hline $\begin{array}{l}\text { Diabetes } \\
\text { mellitus }\end{array}$ & $19(9.5 \%)$ & $22(23.4 \%)$ & $0.001 *$ \\
\hline Dyslipidemia & $2(1 \%)$ & $0(0 \%)$ & 0.331 \\
\hline Hypertension & $41(20.5 \%)$ & $30(31.9 \%)$ & $0.033^{*}$ \\
\hline Smoking & $75(37.5 \%)$ & $31(33 \%)$ & 0.451 \\
\hline $\begin{array}{l}\text { Family history } \\
\text { CAD }\end{array}$ & $14(7 \%)$ & $9(9.6 \%)$ & 0.443 \\
\hline $\begin{array}{l}\text { Currently on } \\
\text { dialysis }\end{array}$ & $0(0 \%)$ & $2(2.1 \%)$ & $0.038 *$ \\
\hline $\begin{array}{l}\text { Chronic lung } \\
\text { disease }\end{array}$ & $1(0.5 \%)$ & $0(0 \%)$ & 0.492 \\
\hline \multicolumn{4}{|l|}{ Culprit Artery } \\
\hline $\begin{array}{l}\text { Left anterior } \\
\text { descending } \\
\text { artery (LAD) }\end{array}$ & $155(77.5 \%)$ & $48(51.1 \%)$ & \multirow{4}{*}{$<0.001$} \\
\hline $\begin{array}{l}\text { Right coronary } \\
\text { artery (RCA) }\end{array}$ & $33(16.5 \%)$ & $33(35.1 \%)$ & \\
\hline $\begin{array}{l}\text { Circumflex } \\
\text { artery }(\mathrm{LCX})\end{array}$ & $10(5 \%)$ & $11(11.7 \%)$ & \\
\hline Left Main (LM) & $2(1 \%)$ & $2(2.1 \%)$ & \\
\hline
\end{tabular}


It is evident from Table 2 that patients without MVD were more likely smokers and males and had a high median SBP than patients with MVD. However, patients with MVD were older and more likely to have DM and HTN than their counterparts.

To determine the predictors of MVD, we performed a logistic regression analysis of all variables. Only age and DM were found to be significant independent predictors of MVD, as shown in Table 3. The risk of developing MVD was higher in diabetics with unadjusted and adjusted ORs and 95\% CIs of 2.91 [1.49-5.7], p-value $=0.002$, and 2.47 [1.23-4.97], pvalue $=0.011$.

Table 3: Determinants of multivessel disease

\begin{tabular}{|l|c|c|c|c|}
\hline & \multicolumn{2}{|c|}{ Unadjusted } & \multicolumn{2}{c|}{ Adjusted } \\
\cline { 2 - 5 } & $\begin{array}{c}\text { OR } \\
{[\mathbf{9 5 \%} \text { CI] }}\end{array}$ & $\begin{array}{c}\text { p- } \\
\text { value }\end{array}$ & $\begin{array}{c}\text { OR } \\
{[\mathbf{9 5 \%} \text { CI] }}\end{array}$ & $\begin{array}{c}\text { p- } \\
\text { value }\end{array}$ \\
\hline Age (years) & $\begin{array}{c}1.11 \\
{[1.04-1.19]}\end{array}$ & $0.003 *$ & $\begin{array}{c}1.1 \\
{[1.02-1.17]}\end{array}$ & $\begin{array}{c}0.009 \\
*\end{array}$ \\
\hline BMI $\left(\mathrm{kg} / \mathrm{m}^{2}\right)$ & $\begin{array}{c}1.03 \\
{[0.97-1.1]}\end{array}$ & 0.353 & - & - \\
\hline Male gender & $\begin{array}{c}0.7 \\
{[0.31-1.56]}\end{array}$ & 0.385 & - & - \\
\hline $\begin{array}{l}\text { Diabetes } \\
\text { mellitus }\end{array}$ & $\begin{array}{c}2.91 \\
{[1.49-5.7]}\end{array}$ & $0.002 *$ & $\begin{array}{c}2.47 \\
{[1.23-4.97]}\end{array}$ & $\begin{array}{c}0.011 \\
*\end{array}$ \\
\hline HTN & $\begin{array}{c}1.82 \\
{[1.05-3.16]}\end{array}$ & $0.034 *$ & $\begin{array}{c}1.37 \\
{[0.76-2.47]}\end{array}$ & 0.289 \\
\hline Smoking & $\begin{array}{c}0.82 \\
{[0.49-1.37]}\end{array}$ & 0.452 & - & - \\
\hline $\begin{array}{l}\text { Family } \\
\text { history CAD }\end{array}$ & $\begin{array}{c}1.41 \\
{[0.59-3.38]}\end{array}$ & 0.445 & - & - \\
\hline
\end{tabular}

$B M I=$ body mass index, $H T N=$ hypertension, $C A D=$ coronary artery diseases, $C I=$ confidence interval

*significant at $5 \%$

\section{DISCUSSION}

Although risk factors for ACS in young adults have been studied in detail, risk factors for multivessel CAD in young adults have not been explored in our country. It has been postulated that the multivessel disease in patients presenting for primary PCI is directly indicative of significantly higher postprocedure complications, mortality, morbidity, and prolonged hospitalization. ${ }^{14}$ Therefore, it is imperative to ascertain risk factors and independent predictors of MVD. This study aimed to identify predictors of MVD in Pakistani adults presenting with premature CAD. The risk factor profile of CAD in young patients appears to be different from that in elderly patients. Several studies have reported a significant association of HTN, as well as smoking, with CAD in young adults. ${ }^{17-19}$ In 2014, Mirza et al. reported obesity as the most prevalent risk factor in the young Iraqi population among other factors, such as HTN, smoking, DM, and positive family history. ${ }^{18}$ Konishi and colleagues found that current smoking and obesity were two clinical determinants of young Japanese patients who underwent PCI, whereas HTN was not proven to be a predictor of CAD in young adults. ${ }^{8} \mathrm{We}$ proved that DM and age are independent predictors of MVD in adults with premature CAD.

$\mathrm{Ge} \mathrm{J}$ et al. highlighted the role of HTN in young adults and proved that HTN was an independent risk factor for MV CAD in young adults with ACS. He also concluded that HTN led to a higher MACE rate during short-term follow-up. ${ }^{13}$ Ge J et al. reported HTN and smoking as independent predictors of MVD in his study, in contrast to our study, which does not prove that HTN is a predictor of MVD in young Pakistani adults presenting with STEMI. However, similar to our study findings, Shukija et al. also reported a higher prevalence of MVD in HTN patients than in nonhypertensive patients. ${ }^{20}$

Our mean age was reported as $35.4 \pm 4.07$ years, which was higher than the mean age of $31.4 \pm 3.5$ years shown in a study published by Anjum and colleagues on Pakistani young adults presenting with acute MI. However, the prevalence of premature CAD among males was similar in both studies $(90.5 \%$ vs. $88.2 \%){ }^{21}$ A study performed in young females to observe the presentations and risk factors for CAD in India published mean ages of $37.9 \pm 7.3$ in females and 40.5 \pm 4.3 in males, but the frequency of CAD in males was lower $(79 \%)$ than our data $(90.5 \%){ }^{22}$ Our study, however, indicates that age is an independent predictor of MVD in young Pakistani adults presenting with CAD.

Chua $\mathrm{S}$ et al. postulated the role of obesity in young adults presenting with STEMI and showed that BMI $\geq$ $27 \mathrm{~kg} / \mathrm{m}^{2}$ was more likely associated with premature CAD than older adults with STEMI $(48.2 \%$ vs. 27.9\%). Although the prevalence of MVD was lower $(31.9 \%)$ in our study than in the study by Chua $\mathrm{S}$ et al. (45.4\%), the median BMI of our patients was 26.2 in the MVD group vs. 25.7 in the SVD group. ${ }^{23}$ Surprisingly, the prevalence of dyslipidemia was very low $(0.7 \%)$ in our young patients with premature CAD in comparison with the higher frequency $(28.3 \%)$ reported by Chua and colleagues. ${ }^{23}$ However, we failed to establish any association of MVD with obesity and dyslipidemia in young adults with CAD, and we emphasize exploring these risk factors and their association with MVD in adults $<40$ years old in larger clinical trials.

Parsa et al. reported $89.1 \%$ diabetics in the MVD group and $10.9 \%$ in the SVD group, in contrast to our lower prevalence of diabetics in the MVD (23.4\%) and SVD $(9.5 \%)$ groups. $^{24}$ We also observed a low $(13.9 \%)$ overall prevalence of DM in our patients with 
premature $\mathrm{CAD}$, similar to the prevalence (15.2\%) reported by Ergelen and associates in a study performed the compare outcomes in young versus older patients with STEMI. He also elaborated that DM and MVD were independent predictors of cardiovascular mortality among all age groups, including young adults. ${ }^{5} \mathrm{We}$ also established that DM is a significant risk factor and predictor of MVD in young adults presenting with STEMI.

The demographic characteristics of our patients also differed when we compared the frequency of smoking. We observed 33\% smokers in the MVD group and $37.5 \%$ in the SVD group, in contrast to the higher prevalence rates of smoking reported by Parsa and colleagues $(63.5 \%$ in the MVD group and $36.5 \%$ in the SVD group). ${ }^{24}$ Regardless of the prevalence, we were unable to find any significant association of smoking with MVD in our patients with premature CAD. The prevalence of smoking was also found to be higher in young patients with CAD than in old patients in data published by Hirota $\mathrm{Y}$ et al. yet smoking was not found to be a predictor of CAD in young adults. However, they proved that MVD was associated with higher inhospital mortality and cardiogenic shock. ${ }^{25}$

Despite the low prevalence of traditional risk factors in our study population, $32 \%$ of patients had MVD compared to $68 \%$ of patients with SVD. Nevertheless, larger clinical trials are necessary in the young Pakistani population to identify the cause of the low prevalence of traditional risk factors in this population with severe CAD. A genetic contribution cannot be underestimated in young adults with a propensity to develop multivessel CAD. Needless to say, this study leaves a question mark on the low prevalence of traditional risk factors that needs to be solved. Indeed, our study will become a foundation stone for future researchers in Pakistan. In addition to age, DM also proved to be a predictor of premature multivessel CAD in our study. However, none of the other risk factors, such as obesity, male gender or smoking, were found to be significantly associated with MVD in our young adults who presented with STEMI.

There are certain limitations of this study. First, this is a single-center study, and the severity of premature CAD will require larger multicenter clinical trials to extrapolate the results of this study. Second, this was a retrospective study, which limits its usefulness. Another important limiting factor was the lack of correlation of the severity of CAD with other standard measures of severity, such as the SYNTAX score. However, we consider this effort as the tip of the iceberg and hope that risk factor modification will be addressed with due stress in the future to prevent premature CAD.

\section{CONCLUSION}

In conclusion, we showed that age and DM are independent predictors of MVD in a young Pakistani adult population presenting with STEMI. However, none of the other risk factors, such as obesity, male gender or smoking, were found to be significantly associated with MVD in Pakistani adults with premature CAD. Although significantly associated, HTN does not prove to be an independent predictor of multivessel CAD in young adults.

\section{AUTHORS' CONTRIBUTION}

AM: Concept and design, data acquisition, interpretation, drafting, final approval, and agree to be accountable for all aspects of the work. SZ, ASM, FF, AA, JUR, and TS: Data acquisition, interpretation, drafting, final approval and agree to be accountable for all aspects of the work.

Conflict of interest: Authors declared no conflict of interest.

\section{REFERENCES}

1. Rallidis LS, Pavlakis G, Foscolou A, Kotakos C, Katsimardos A, et al. High levels of lipoprotein (a) and premature acute coronary syndrome. Atherosclerosis. 2018;269:29-34.

2. Yunyun W, Tong L, Yingwu L, Bojiang L, Yu W, Xiaomin H, et al. Analysis of risk factors of ST-segment elevation myocardial infarction in young patients. BMC Cardiovasc Disord. 2014; $14: 179$.

3. Cantarelli MJ, Castello Jr HJ, Gonçalves R, Gioppato S, Navarro E, Guimarães JB, et al. Percutaneous Coronary Intervention in Young Patients. Rev Bras Cardiol Invasiva. 2014;22:353-8.

4. Christus T, Shukkur AM, Rashdan I, Koshy T, Alanbaei M, Zubaid M, et al. Coronary artery disease in patients aged 35 or less-a different beast?. Heart Views. 2011;12:7-11.

5. Ergelen M, Uyarel H, Gorgulu S, Norgaz T, Ayhan E, Akkaya E, et al.. Comparison of outcomes in young versus nonyoung patients with ST elevation myocardial infarction treated by primary angioplasty. Coronary Artery Dis. 2010;21:72-7.

6. Manzil AS, Radhakrishnan V, Rajan JS. Clinical Outcomes and Risk Factor in Patients with STEMI Treated with Percutaneous Coronary Intervention. Int J Clin Med. 2015;6:753.

7. Rathod KS, Jones DA, Gallagher S, Rathod VS, Weerackody R, Jain AK, et al. Atypical risk factor profile and excellent long-term outcomes of young patients treated with primary percutaneous coronary intervention for ST-elevation myocardial infarction. Eur Heart J Acute Cardiovasc Care. 2016;5:23-32.

8. Konishi H, Miyauchi K, Kasai T, Tsuboi S, Ogita M, Naito R, et al. Long-term prognosis and clinical characteristics of young adults $(\leq 40$ years old) who underwent percutaneous coronary intervention. J Cardiol. 2014;64:171-4.

9. Avezum A, Makdisse M, Spencer F, Gore JM, Fox KA, Montalescot G, et al. Impact of age on management and outcome of acute coronary syndrome: observations from the Global Registry of Acute Coronary Events (GRACE). Am Heart J. 2005;149:67-73.

10. Garoufalis S, Kouvaras G, Vitsias G, Perdikouris K, Markatou P, Hatzisavas $\mathrm{J}$, et al. Comparison of angiographic findings, risk factors, and long term follow-up between young and old patients with a history of myocardial infarction. Int J Cardiol. 1998;67:7580 . 
11. Zimmerman FH, Cameron A, Fisher LD, Grace NG: Myocardial infarction in young adults: angiographic characterization, risk factors and prognosis (Coronary Artery Surgery Study Registry). J Am Coll Cardiol. 1995;26:654-61.

12. Lessa I. Trends in productive years of life lost to premature mortality due to coronary heart disease. Arq Bras Cardiol. 2002;79:617-22.

13. Ge J, Li J, Yu H, Hou B. Hypertension Is an Independent Predictor of Multivessel Coronary Artery Disease in Young Adults with Acute Coronary Syndrome. Int J Hypertens. 2018;2018:e7623639.

14. Batra MK, Rasool SI, Solangi BA, Khan N, Karim M, Hassan SR. Multivessel Disease As A Prognostic Marker In Patients Presenting For Primary Percutaneous Coronary Intervention. J Ayub Med Coll Abbottabad. 2018;30:534-8.

15. Levine GN, Bates ER, Blankenship JC, Bailey SR, Bittl JA, Cercek B, et al. 2015 ACC/AHA/SCAI Focused Update on Primary Percutaneous Coronary Intervention for Patients With ST-Elevation Myocardial Infarction: An Update of the 2011 ACCF/AHA/SCAI Guideline for Percutaneous Coronary Intervention and the 2013 ACCF/AHA Guideline for the Management of ST-Elevation Myocardial Infarction: A Report of the American College of Cardiology/American Heart Association Task Force on Clinical Practice Guidelines and the Society for Cardiovascular Angiography and Interventions. Circulation. 2016;133:1135-47.

16. James PA, Oparil S, Carter BL, Cushman WC, DennisonHimmelfarb C, Handler J, et al. 2014 Evidence-Based Guideline for the Management of High Blood Pressure in Adults. JAMA. 2014;311:507-20.

17. Garvey WT, Mechanick JI, Brett EM, Garber AJ, Hurley DL, Jastreboff AM, et al. American association of clinical endocrinologists and American college of endocrinology comprehensive clinical practice guidelines for medical care of patients with obesity. Endocr Pract. 2016;22:1-203.

18. Stone NJ, Robinson JG, Lichtenstein AH, Bairey Merz CN, Blum $\mathrm{CB}$, Eckel RH, et al. 2013 ACC/AHA guideline on the treatment of blood cholesterol to reduce atherosclerotic cardiovascular risk in adults: a report of the American College of Cardiology/American Heart Association Task Force on Practice Guidelines. J Am Coll Cardiol. 2014;63:2889-934.

19. Aggarwal A, Srivastava S, Velmurugan M. Newer perspectives of coronary artery disease in young. World J Cardiol. 2016;8:728-34.

20. Yılmaz S, Gündüz H, Varım P, Vatan MB, Demirtaş S, Çakar $\mathrm{MA}$, et al. A study of coronary artery disease in young patients. Folia Cardiologica. 2017;12:543-50.

21. Anjum M, Zaman M, Fareedullah. Are their young coronaries old enough? Angiographic findings in young patients with acute myocardial infarction. J Ayub Med Coll Abbottabad. 2019;31:151-5.

22. Kher M, Sathyanarayan BC. Coronary Artery Disease in Young Females: Current Scenario. Indian J Cardiovasc Dis WomenWINCARS. 2017;2:39-43.

23. Chua SK, Hung HF, Shyu KG, Cheng JJ, Chiu CZ, Chang CM, et al. Acute ST-elevation Myocardial Infarction in Young Patients: 15 Years of experience in a Single Center. Clin Cardiol. 2010;33:140-8

24. Parsa AFZ, Ziai H, Haghighi L. The impact of cardiovascular risk factors on the site and extent of coronary artery disease. Cardiovasc J Afr. 2012;23:197-9.

25. Hirota Y, Sawano M, Numasawa Y, Ueda I, Noma S, Suzuki M, et al. Characteristics and in-hospital outcomes in young patients presenting with acute coronary syndrome treated by percutaneous coronary intervention. Cardiovasc Interv Ther. 2018;33:154-62.

\section{Address for Correspondence:}

Dr. Ayaz Mir, Senior Registrar at National Institute of Cardiovascular Diseases (NICVD), Karachi, Pakistan.

Email: $\underline{\text { mir_smcian@yahoo.com }}$ 